\title{
Depressão em pacientes HIV positivos: a realidade de um hospital português
}

\author{
Depression in HIV-positive patients: the reality of a Portuguese hospital
}

\author{
Paulina Freitas ${ }^{1}$, André Fernandes ${ }^{1,2}$, Pedro Morgado ${ }^{1,3} \bowtie$
}

${ }^{1}$ Escola de Ciências da Saúde, Universidade do Minho, Braga, Portugal

2 Unidade de Saúde Familiar Manuel Rocha Peixoto, Braga, Portugal

${ }^{3}$ Hospital de Braga, Braga, Portugal

\section{RESUMO}

Objetivos: A depressão constitui a mais frequente perturbação psiquiátrica entre indivíduos infectados pelo HIV. Este trabalho pretende caracterizar a população de doentes HIV positivos da clínica de infectologia do Hospital de Joaquim Urbano do Porto quanto ao perfil de sintomas depressivos e verificar se estes se correlacionam com os parâmetros analíticos mais frequentemente avaliados no contexto da infecção por este vírus: carga viral do HIV, contagem e percentagem de linfócitos CD4+.

Métodos: Foi realizado um estudo observacional descritivo e analítico. Os níveis de sintomas depressivos dos participantes foram avaliados com o Inventário Depressivo de Beck. Os antecedentes patológicos, psiquiátricos e os valores analíticos da carga viral, contagem e percentagem de CD4+ foram obtidos através de consulta aos respectivos processos clínicos.

Resultados: Foi encontrada uma prevalência de $65,5 \%$ de sintomas depressivos, com uma percentagem considerável (32,7\%) dos indivíduos apresentando sintomas graves. Não se verificaram associações entre os níveis de sintomas depressivos e a contagem de CD4+, percentagem de CD4+ ou carga viral. Foram, no entanto, demonstradas associações entre sintomas depressivos, toxicodependência e grau de escolaridade.

Conclusões: A elevada prevalência de sintomas depressivos encontrada neste estudo reforça a importância da vigilância desse tipo de sintomatologia em indivíduos HIV positivos. O fato de não se terem verificado associações entre sintomas depressivos e os parâmetros analíticos avaliados está em conformidade com estudos anteriores.

DESCRITORES: depressão; sintomas depressivos; HIV; soropositividade para HIV; linfócitos T CD4-positivos; carga viral.

\section{ABSTRACT}

Aims: Depression is the most common psychiatric disorder among people infected with HIV. This study aims to characterize the Hospital of Joaquim Urbano population of HIV-infected patients' profile regarding depressive symptoms and whether they correlate with the analytical parameters most frequently evaluated in the context of infection by this virus - HIV viral load, CD4+ count and CD4+ percentage.

Methods: We conducted an observational descriptive and analytical study. The participants' level of depressive symptoms was assessed with the Beck Depression Inventory. The medical and psychiatric history and the analytical values of viral load, CD4+ count and CD4+ percentage were obtained by consulting the participants' clinical processes.

Results: A prevalence of $65.5 \%$ in HIV-infected patients' depressive symptoms was found, with a considerable high percentage of subjects presenting with severe symptoms (32.7\%). No associations between the depressive symptoms' levels and CD4+ count, CD4+ percentage or viral load were found. However, depressive symptoms were associated with substance abuse and education level.

Conclusions: The high prevalence of depressive symptoms found in this study reinforces the importance of monitoring this type of symptoms in HIV-infected subjects. The fact that there have been no associations between depressive symptoms and the analytical parameters evaluated is in line with previous studies.

KEY WORDS: depression; depressive symptoms; HIV; HIV seropositivity; CD4-positive T-lymphocytes; viral load. 
Abreviaturas: HIV, vírus da imunodeficiência humana; SIDA, síndrome da imunodeficiência adquirida; TARV, terapêtica antirretroviral; BDI, Inventário de Depressão de Beck (Beck Depression Inventory); HJU, Hospital de Joaquim Urbano; CDC, Centers for Disease Control and Prevention.

\section{INTRODUÇÃO}

Aproximadamente 34 milhões de pessoas vivem com o HIV/síndrome da imunodeficiência adquirida (SIDA) [1]. Graças à eficácia das novas terapêuticas antirretrovirais (TARV), a infecção pelo HIV tornouse uma situação crônica, o que se tem traduzido em aumento significativo da esperança média de vida em indivíduos infectados pelo vírus [2-4]. Dessa forma, começam a se tornar mais frequentes apresentações clínicas do HIV que antes não tinham tempo para se desenvolver, incluindo diversas manifestações neuropsiquiátricas [5]. Neste grupo, as perturbações de foro depressivo são as mais frequentes [5-7]. Vários estudos demonstraram que a prevalência de depressão major é mais elevada em indivíduos HIV positivos do que na população geral $[3,4]$. Apesar disso, esta patologia continua subdiagnosticada e subtratada $[5,6]$.

As complexas circunstâncias biológicas e psicossociais inerentes à infecção por HIV, associadas ao fato de os sintomas vegetativos presentes na depressão (fadiga, dor, anorexia e insônia) serem característicos da progressão natural da infecção, podem explicar a dificuldade que existe em reconhecer esta perturbação psiquiátrica nesta população de doentes $[3,8]$. Não obstante, estima-se que aproximadamente metade dos doentes infectados pelo HIV apresente diagnóstico concomitante de patologia psiquiátrica e que destes, cerca de $50 \%$ permaneçam sem tratamento $[3,9]$. Vitiello et al. [5] demonstraram-no em um estudo cujos resultados indicam que apenas $43 \%$ de uma amostra de 1561 doentes seropositivos com diagnóstico de depressão ou distimia se encontrava medicada com antidepressivo, o que sustenta o fato de que, mesmo após detecção de distúrbios psiquiátricos, estes permaneçam por tratar [5].

Adicionalmente, existe grande preocupação entre a comunidade médica relativamente à segurança e interacções medicamentosas entre os fármacos que compõem a TARV e os psicotrópicos, existindo ainda poucos estudos realizados neste âmbito [3]. Ainda assim, há quem defenda que essas interacções farmacológicas serão pouco significativas, dando ênfase à necessidade de tratar a depressão nesses doentes [9]. A depressão é atualmente reconhecida como uma das causas do aumento da morbimortalidade em doenças crônicas orgânicas, havendo evidências de que o stress crônico e o coping disfuncional afetam o sistema imunológico, ao exercer efeitos potencialmente nefastos na imunidade celular [5].

A infecção pelo HIV pode constituir-se como um fator etiológico para o desenvolvimento de perturbações psiquiátricas ou para a exacerbação de condições préexistentes, nomeadamente do foro depressivo $[10,11]$. Esta hipótese é suportada pelos achados de um estudo que demonstrou início de depressão mais tardio em doentes HIV positivos do que em indivíduos não infectados, tornando mais provável que esse distúrbio seja secundário à infeção [6]. Vários são os mecanismos que explicam a maior susceptibilidade dos doentes HIV positivos à depressão, sendo estes de natureza: 1) fisiológica (doença sistêmica, infecções oportunistas, tumores do sistema nervoso central, efeitos diretos do vírus no cérebro); 2) farmacológica (efeitos colaterais da TARV); e 3) sociocomportamental (estigma e discriminação social, medo da morte) [10-12].

Por outro lado, a própria depressão parece influenciar a doença por HIV, favorecendo a sua progressão e estando associada ao agravamento da taxa de mortalidade $[3,13]$. Um grupo de investigação demonstrou efeitos significativos do stress em parâmetros da imunidade celular, tendo os sintomas depressivos sido relacionados com o declínio de vários subtipos linfocitários em homens soropositivos [5]. Os sintomas depressivos foram também associados à mais rápida progressão da infecção por HIV e ao declínio acelerado da função imune, com diminuição significativa da contagem de linfócitos T CD4+ $[11,14]$. No entanto, os estudos realizados no sentido de averiguar os efeitos da depressão na infecção pelo HIV têm mostrado resultados contraditórios. Enquanto alguns estudos mostram haver associação entre os níveis de CD4+ e a gravidade da depressão, outros rejeitam esta hipótese, não encontrando qualquer relação entre a gravidade dos sintomas depressivos e os parâmetros analíticos relacionados com a infecção pelo HIV [6,8]. Várias investigações demonstraram que o reconhecimento e tratamento precoces de depressão em pacientes soropositivos atrasam a progressão da infecção para fase de SIDA e melhoram a adesão terapêutica $[6,18]$.

Sendo a depressão uma entidade prevalente que se encontra subdiagnosticada em doentes HIV positivos, e tendo em conta a escassez de estudos sobre este tema em Portugal, torna-se importante caracterizar a população portuguesa de doentes soropositivos no que toca à prevalência dessa psicopatologia. Assim, pretendemos caracterizar a população de doentes HIV 
porsitivos do Hospital de Joaquim Urbano (HJU) do Porto quanto a sintomas depressivos e verificar se estes se correlacionam com os parâmetros de infeção pelo HIV mais frequentemente avaliados (carga viral do HIV, contagem e percentagem de CD4+).

\section{MÉTODOS}

Foi realizado um estudo transversal cuja população foi composta pelos pacientes HIV positivos que frequentavam a clínica de infectologia do HJU, entre 01 de outubro e 30 de novembro de 2011. O projeto obteve aprovação institucional em harmonia com as normas éticas e legais em vigor à data da sua realização. Todos os participantes assinaram documento de consentimento informado.

Entre os pacientes HIV positivos seguidos na clínica de infectologia no HJU, foram seleccionados indivíduos com mais de 18 anos que aceitaram voluntariamente participar da investigação. Foram excluídos do estudo os indivíduos que apresentassem diagnóstico de infecção pelo HIV há menos de um mês, doença aguda, déficit cognitivo que impedisse a adequada compreensão do questionário a aplicar ou que estivessem sob terapêutica com interferon.

Os pacientes eram convidados a participar do estudo pelos profissionais de saúde do HJU (médicos, enfermeiros e assistente social). Aqueles que se mostravam dispostos a cooperar eram encaminhados para um consultório, onde, na presença unicamente da investigadora, o estudo lhes era devidamente explicado. Após obtenção do consentimento informado, os participantes passavam ao preenchimento de um questionário.

Foi aplicado um questionário de auto-preenchimento que englobava informação sociodemográfica (idade, gênero, orientação sexual, estado civil, grau de instrução e profissão atual) e o Inventário de Depressão de Beck (Beck Depression Inventory: BDI) validado para português em 1973 por Vaz Serra e Pio Abreu [19].

O BDI é constituído por 21 itens que avaliam seis domínios frequentemente alterados nos estados depressivos: componentes afetivo, cognitivo, motivacional, delirante, físico e desvio funcional depressivo. Em cada item, o indivíduo deve escolher uma das quatro ou cinco afirmações que seja aquela que mais se assemelha ao seu estado atual. A cada afirmação corresponde uma pontuação de zero a três, conforme o grau de gravidade do sintoma [20]. De acordo com a pontuação total obtida no BDI, classificam-se os sintomas depressivos apresentados pelo sujeito com base numa escala, em que 12 é o valor acima do qual se diferenciam indivíduos deprimidos de não deprimidos (0-12 pontos: sem sintomas; $13-18$ pontos: sintomas leves; 19-24 pontos: sintomas moderados; $>24$ pontos: sintomas graves) [21].

Os dados relativos a antecedentes patológicos e psiquiátricos dos participantes, bem como resultados analíticos e história de infecção pelo HIV foram obtidos através de consulta direta aos respectivos prontuários.

A análise estatística dos dados foi efetuada com a versão 19 do programa Statistical Package for the Social Sciences. Quanto à análise descritiva, foram determinadas a média, desvio-padrão, mediana e valores mínimo e máximo para as variáveis quantitativas; relativamente às variáveis ordinais, foram calculadas as frequências, mediana, moda e intervalos interquartílicos; finalmente, para as variáveis nominais foram determinadas as frequências e a moda. Para as variáveis quantitativas foram utilizados os testes de Kolmogorov-Smirnov e de Levene para testar a normalidade da distribuição amostral e a homogeneidade de variâncias, respectivamente.

Para verificar as possíveis diferenças existentes entre os diferentes grupos de indivíduos quanto a variáveis quantitativas com distribuição normal, foram utilizados os testes $t$-Student e ANOVA one-way. Para as variáveis nominais, ordinais e quantitativas que não cumpriram as condições para serem submetidas aos testes paramétricos, foram utilizados os testes de Mann-Whitney e de Kruskal-Wallis (equivalentes não paramétricos dos testes supramencionados).

Para determinar as possíveis associações existentes entre os grupos de indivíduos com diferentes níveis de sintomas depressivos relativamente aos parâmetros analíticos da infecção HIV e aos parâmetros sociodemográficos avaliados, foram calculados os respectivos coeficientes de correlação de Spearman.

Foi ainda realizado o teste binomial para testar a existência de diferenças entre as proporções de indivíduos com sintomas depressivos e sem sintomas depressivos.

A significância estatística foi definida para valores de $\mathrm{p} \leq 0,05$.

\section{RESULTADOS}

\section{População do estudo}

No período de realização do estudo eram acompanhados no HJU 3374 pacientes infectados por HIV, sendo $801(23,7 \%)$ indivíduos do sexo feminino e $2573(76,3 \%)$ do sexo masculino. A média da idade 
informada para a população foi de 32,9 anos (32 no caso das mulheres e 33,2 no caso dos homens).

Considerando as principais vias de transmissão do HIV nessa população de 3374 indivíduos infectados, $63,4 \%$ dos homens e $56,4 \%$ das mulheres apresentavam risco de toxicodependência endovenosa, $17,2 \%$ dos homens e $50,6 \%$ das mulheres risco heterossexual e $12,1 \%$ dos homens e $1,5 \%$ das mulheres risco homossexual. Trezentos indivíduos (189 do sexo masculino e 111 do sexo feminino) foram infectados por outra via (transmissão mãe-filho ou transfusões sanguíneas) ou apresentavam risco desconhecido para a infecção pelo HIV.

Após a aplicação dos critérios de inclusão e exclusão, foi selecionada uma amostra de 107 participantes, 87 $(81,3 \%)$ do sexo masculino e $20(18,7 \%)$ do sexo feminino. Os participantes apresentavam uma idade média de 42,8 $\pm 8,3$ anos ( mediana $=42 ;$ mínima $=23$; máxima $=74$ ).

A Tabela 1 resume características sociodemográficas da amostra incluída no estudo. O nível de escolaridade era baixo (mediana $=6$ anos). Apenas $10(9,3 \%)$ indivíduos possuíam 12 ou mais anos de escolaridade, sendo que os restantes 97 (90,7\%) possuíam $\leq 9$ anos de escolaridade completos. Quanto à situação profissional, $52(48,6 \%)$ indivíduos se encontravam em atividade laboral. Vinte e dois pacientes $(20,6 \%)$ eram aposentados, sendo que destes, $21(95,5 \%)$ tinham idade inferior a 65 anos. Verificouse uma predominância de sujeitos sem companheiro ou companheira, com os indivíduos casados ou em união estável representando $23,4 \%$ da amostra. Relativamente à orientação sexual, a grande maioria dos indivíduos, 98 (91,6\%) referia ser heterossexual, com seis $(5,6 \%)$ informando ser homossexuais e três $(2,8 \%)$ bissexuais.

\section{Comorbidades}

Verificou-se nessa amostra uma grande proporção de indivíduos coinfectados pelo vírus da hepatite $\mathrm{C}$ (HCV): 89 (83\%). Adicionalmente, 32 (29,9\%) indivíduos apresentavam outras comorbidades orgânicas: Diabetes mellitus tipos 1 e 2, hipertensão arterial sistêmica (HAS), dislipidemia, asma e insuficiência hepática.

As características da amostra em relação ao perfil de comorbidades psiquiátricas encontram-se resumidas na Tabela 2. Salienta-se o fato de $83,2 \%$ dos indivíduos (65,0\% das mulheres e $87,4 \%$ dos homens) da amostra terem antecedentes de toxicodependência, dos quais $14,6 \%$ mantinham consumo ativo.

Trinta e duas (30,0\%) mulheres e 14 (13,08\%) homens tinham antecedentes de doença depressiva $(\mathrm{p}=0,082)$. Outra patologia psiquiátrica estava presente em $21(20,0 \%)$ mulheres e em sete $(6,9 \%)$ homens $(\mathrm{p}=0,071)$.

No total, 26 (24,3\%) indivíduos recebiam medicação psiquiátrica. Quanto a este aspecto, 21 (19,6\%) pacientes encontravam-se sob terapêutica ansiolítica, sendo esta a classe de fármacos psicotrópicos mais representada. Sete indivíduos $(6,5 \%)$ encontravam-se medicados com antidepressivo, e o mesmo número encontrava-se medicado com antipsicóticos. No que diz respeito à medicação com mais de um tipo de psicofármaco, três indivíduos encontravam-se sob terapêutica ansiolítica e antidepressiva, três eram medicados com antidepressivo e antipsicótico e dois com uma combinação das três classes de fármacos.
Tabela 1. Resumo das características sociodemográficas da amostra composta por pacientes HIV positivos com 18 anos de idade ou mais, atendidos no Hospital de Joaquim Urbano, Porto, Portugal, entre 01 de outubro e 30 de novembro de 2011.

\begin{tabular}{|c|c|c|c|c|}
\hline Características & $\begin{array}{l}\text { Mulheres } \\
(\mathrm{N}=20)\end{array}$ & $\begin{array}{c}\text { Homens } \\
(\mathrm{N}=87)\end{array}$ & $\begin{array}{c}\text { Total } \\
(\mathbf{N}=\mathbf{1 0 7})\end{array}$ & $\%$ \\
\hline \multicolumn{5}{|l|}{ Escolaridade } \\
\hline$\leq 4$ anos & 5 & 33 & 38 & 35,5 \\
\hline 6 anos & 8 & 29 & 37 & 34,6 \\
\hline 9 anos & 7 & 15 & 22 & 20,6 \\
\hline$\geq 12$ anos & - & 10 & 10 & 9,3 \\
\hline \multicolumn{5}{|l|}{ Situação profissional } \\
\hline Empregado(a) & 10 & 42 & 52 & 48,6 \\
\hline Desempregado(a) & 9 & 24 & 33 & 30,8 \\
\hline Reformado(a) & 1 & 21 & 22 & 20,6 \\
\hline \multicolumn{5}{|l|}{ Estado civil } \\
\hline Solteiro(a) & 4 & 53 & 57 & 53,3 \\
\hline Casado(a)/União de facto & 9 & 16 & 25 & 23,4 \\
\hline Divorciado(a)/Separado(a)/Viúvo(a) & 7 & 18 & 25 & 23,4 \\
\hline \multicolumn{5}{|l|}{ Orientação sexual } \\
\hline Heterossexual & 19 & 79 & 98 & 91,6 \\
\hline Homossexual & - & 6 & 6 & 5,6 \\
\hline Bissexual & 1 & 2 & 3 & 2,8 \\
\hline
\end{tabular}


Tabela 2. Perfil de comorbidades psiquiátricas pacientes HIV positivos com 18 anos de idade ou mais, atendidos no Hospital de Joaquim Urbano, Porto, Portugal, entre 01 de outubro e 30 de novembro de 2011.

\begin{tabular}{lcc|cc}
\hline \multicolumn{1}{c}{ Comorbidades psiquiátricas } & Mulheres & Homens & N & $\%$ \\
\hline Antecedentes de depressão & 6 & 12 & 18 & 16,8 \\
\hline Toxicodependência & 13 & 76 & 89 & 83,2 \\
Consumo atual de drogas & 2 & 11 & 13 & $(14,6)^{*}$ \\
Terapêutica de substituição com metadona & 8 & 61 & 69 & $(77,5)^{*}$ \\
\hline Alcoolismo & 1 & 27 & 28 & 26,2 \\
Consumo atual de álcool & - & 7 & 7 & $(25,0) \dagger$ \\
\hline Outra comorbidade psiquiátrica(1) & 4 & 6 & 10 & 9,3 \\
Esquizofrenia/outras psicoses & 3 & 4 & 7 & $(70,0) \neq$ \\
\hline Terapêutica psicotrópica atual & 7 & 19 & 26 & 24,3 \\
Ansiolítica & 6 & 15 & 21 & 19,6 \\
Antidepressiva & 2 & 5 & 7 & 6,5 \\
Antipsicótica & 3 & 4 & 7 & 6,5 \\
\hline
\end{tabular}

(11) Inclui perturbação bipolar, esquizofrenia ou outras psicoses e patologia psiquiátrica não especificada.

* Percentagens referentes aos indivíduos toxicodependentes $(n=89)$ e não ao $n$ o total de indivíduos.

+ Percentagem referente aos indivíduos alcoólicos $(n=28)$ e não ao no total de indivíduos.

₹ Percentagem referente aos indivíduos que apresentam as comorbilidades psiquiátricas referidas $(n=10)$, e não ao $\mathrm{n}$ o total de indivíduos.

\section{Parâmetros da infecção por HIV}

Todos os 107 indivíduos pertencentes a esta amostra se encontravam infectados pelo HIV do tipo 1 e medicados com TARV. O fator de risco para infecção pelo HIV mais representado nesta amostra foi o consumo de drogas endovenosas $(77,6 \%)$, seguido das relações sexuais desprotegidas heterossexuais $(16,8 \%)$ e homossexuais $(5,6 \%)$.

O tempo médio decorrido desde a data de diagnóstico da infecção por HIV (tempo de infecção) foi de $10,7 \pm 4,8$ anos. O caso mais antigo de infecção havia ocorrido há 21 anos e existiam três indivíduos com diagnóstico de infecção pelo HIV há menos de um ano. Nos homens, o tempo médio de infecção foi de $11 \pm 4,9$ anos (mediana $=12 ;$ mínimo $=0$; máximo $=21$ ) e nas mulheres de $9,4 \pm 4,1$ anos (mediana $=9 ;$ mínima $=3 ;$ máxima $=16$ ).

Relativamente aos parâmetros analíticos da infecção, verificou-se uma média de $466,8 \pm 277,4$ $\mathrm{CD} 4+/ \mathrm{mm}^{3}$. Mais de metade dos indivíduos $(60,8 \%)$ apresentava uma contagem inferior a $500 \mathrm{CD} 4+/ \mathrm{mm}^{3}$ e $18,7 \%$ apresentavam contagens de CD4+ abaixo dos $200 / \mathrm{mm}^{3}$, o que constitui uma das condições definidoras de SIDA, segundo o Centers for Disease Control and Prevention (CDC) [22].

A percentagem de $\mathrm{CD} 4+$ apresentava um valor médio de 23,5 $(10,8)$. Só nove $(8,4 \%)$ indivíduos apresentavam percentagens de CD4+ consideradas normais $(\geq 38 \%)$, em contraposição com os restantes 98 (91,6\%). Adicionalmente, $16,8 \%$ dos indivíduos possuía menos de $14 \%$ de CD4+, o que é considerado critério definidor de SIDA pelo CDC [22].

Devido à grande dispersão dos valores da carga viral, procedeu-se à transformação matemática dessa variável para o seu logaritmo de base 10 [log(HIV)], no sentido de homogeneizar as variâncias. Apesar da modificação efetuada, esta foi a única variável quantitativa que mostrou uma distribuição não normal. No total, 80 indivíduos $(74,8 \%)$ apresentaram carga viral indetectável no sangue ( $<20$ cópias $\left./ \mathrm{mm}^{3}\right)$, o que corresponde a um valor nulo de $\log (\mathrm{HIV})$. O valor máximo foi de 393 mil cópias $/ \mathrm{mm}^{3}$.

\section{Perfil de sintomas depressivos}

A pontuação obtida no BDI serviu de base para a classificação do grau de sintomas depressivos, segundo os pontos de corte anteriormente explicados. A média da pontuação obtida no BDI foi de 19 (12) pontos. A pontuação mínima foi de zero pontos e a máxima de 54. O valor médio das pontuações para indivíduos de ambos os sexos foi de 19 pontos, com desvio-padrão de 12 pontos para os homens e de 15 para as mulheres. Não foram encontradas diferenças estatisticamente significativas entre os dois sexos, relativamente à pontuação obtida no $\mathrm{BDI}(\mathrm{t}=0,11 ; \mathrm{p}=0,99)$.

Foram encontradas diferenças significativas nas pontuações do BDI nos diferentes grupos de risco para a infeção HIV $(p=0,039)$ (Tabela 3). As médias das pontuações foram de $20,5 \pm 11,9$ para o grupo de toxicodependentes, $15,1 \pm 13,9$ para os heterossexuais e $9,7 \pm 9,6$ para os homossexuais. Verificaram-se diferenças marginalmente significativas entre as pontuações médias dos grupos toxicodependente e homossexual $(p=0,093)$, não se tendo verificado diferenças entre toxicodependentes e heterossexuais $(p=0,201)$ nem entre homossexuais e heterossexuais $(\mathrm{p}=0,616)$.

A pontuação do BDI mostrou estar relacionada com a toxicodependência $(p=0,007)$. O grupo de 
toxicodependentes apresentou uma pontuação média de 20,4 em comparação com o grupo não toxicodependente, o qual apresentou um valor médio de 11,9 pontos.

Verificou-se que $70(65,5 \%)$ indivíduos apresentava sintomas depressivos $(p=0,004)$. A prevalência de sintomas depressivos foi de $65,0 \%$ nas mulheres e de $66,7 \%$ nos homens, não sendo esta diferença estatisticamente significativa $(\mathrm{p}=0,328)$.

Quanto às categorias de sintomas, $21(19,6 \%)$ indivíduos apresentam sintomas leves, 13 (12,1\%) sintomas moderados e $35(32,7 \%)$ sintomas graves. A percentagem de indivíduos sem sintomas foi de 35,5\%. Mulheres sem sintomas foram $48(45,0 \%)$ e homens sem sintomas foram $36(33,3 \%)$. Quarenta e oito $(45,0 \%)$ mulheres e $32(29,9 \%)$ homens apresentavam sintomas graves $(\mathrm{p}=0,977)$.

Tabela 3. Resultados dos testes de associação entre a pontuação obtida no Inventário de Depressão de Beck (BDI) e a toxicodependência e os diferentes grupos para o risco de infecção. Pacientes HIV positivos com 18 anos de idade ou mais, atendidos no Hospital de Joaquim Urbano, Porto, Portugal, entre 01 de outubro e 30 de novembro de 2011.

\begin{tabular}{l|ll}
\hline & \multicolumn{2}{|c}{ Pontuação do BDI } \\
\hline Toxicodependência & $\mathrm{t}=-2,735$ & $\mathrm{p}=0,007$ \\
\hline Risco de infecção & $\mathrm{F}=3,352$ & $\mathrm{p}=0,039$ \\
\hline
\end{tabular}

BDI - Inventário de Depressão de Beck

$\mathrm{t}$ - teste $\mathrm{t}$-Student.

p- significância estatística.

$\mathrm{F}$ - teste ANOVA one-way.

\section{Relação entre sintomas depressivos e infecção por HIV}

Relativamente à associação entre sintomas depressivos e parâmetros da infecção HIV, não foram encontradas diferenças significativas entre a contagem de CD4+, percentagem de CD4+ ou carga viral em indivíduos com e sem sintomas depressivos. Da mesma forma, não foram demonstradas relações entre o nível de sintomas depressivos e os parâmetros de infecção referidos (Tabela 4).

Foram também pesquisadas diferenças entre indivíduos com e sem sintomas relativamente ao tempo de infecção, as quais não foram estatisticamente significativas $(p=0,815)$. Não foi, igualmente, demonstrada relação entre o tempo decorrido desde o diagnóstico da infecção e os níveis de sintomas depressivos $(\mathrm{p}=0,781)$.
Tabela 4. Resultados dos testes de associação entre a presença e níveis de sintomas depressivos e os parâmetros da infeção por HIV contagem e percentagem de CD4+ e logaritmo da carga viral, $\log (\mathrm{HIV})$. Pacientes HIV positivos com 18 anos de idade ou mais, atendidos no Hospital de Joaquim Urbano, Porto, Portugal, entre 01 de outubro e 30 de novembro de 2011.

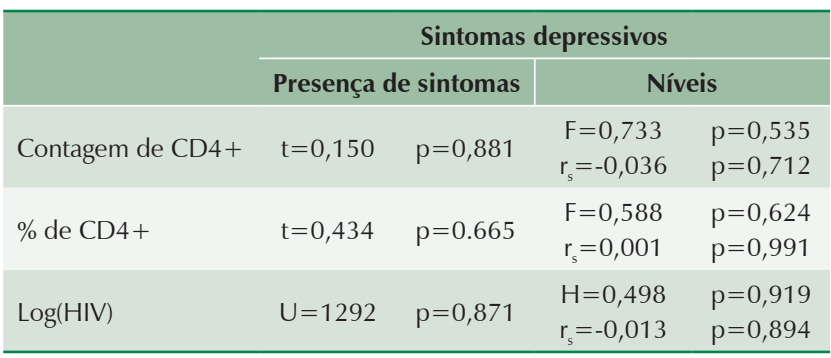

Log(HIV) - logaritmo da carga viral de HIV.

$\mathrm{t}$ - teste t-Student.

p - significância estatística.

U - teste de Mann-Whitney.

- teste de Mann-Whitney.

- teste ANOVA one-way.

$r_{s}$ - coeficiente de correlação de Spearman.

$\mathrm{H}$ - teste Kruskal-Wallis.

\section{Relação entre sintomas depressivos e outros parâmetros abordados}

Foram pesquisadas associações entre os níveis de sintomas depressivos e outros factores contemplados neste estudo, que pudessem afetar o estado depressivo dos indivíduos. Como referido anteriormente, não foram verificadas diferenças estatisticamente significativas entre sexos no que toca à presença de sintomas depressivos ou ao nível dos mesmos $(\mathrm{p}>0,9)$.

Foram encontradas associações marginalmente significativas entre os níveis de depressão e os diferentes grupos de risco para a infecção $(\mathrm{p}=0,085)$ e com a existência de comorbidade psiquiátrica $(\mathrm{p}=0,071)$. Dos 10 indivíduos que apresentam comorbidade psiquiátrica, seis apresentam sintomas de depressão. Dentro dos diferentes grupos de risco, o grupo de toxicodependentes endovenosos constituiu o grupo mais deprimido, com uma prevalência de sintomas de $68,5 \%$. A proporção de sintomas depressivos não diferiu entre os indivíduos de risco homossexual e heterossexual, correspondendo a $50 \%$ dos casos em cada grupo.

Verificou-se existir associação entre a toxicodependência e os diferentes graus de gravidade dos sintomas de depressão $(p=0,022)$. O coeficiente de correlação de Spearman mostrou uma associação positiva estatisticamente significativa entre estas duas variáveis $\left(\mathrm{r}_{\mathrm{s}}=0,222, \mathrm{p}=0,022\right)$.

Foi também encontrada uma correlação negativa significativa entre o nível de escolaridade e os níveis de sintomas depressivos $\left(r_{s}=-0,322, p=0,001\right)$. 
Relativamente às variáveis idade, situação profissional, estado civil, presença de comorbidade orgânica e TARV no momento do estudo, não foi demonstrado estarem relacionadas com os sintomas de depressão $(p>0,5)$.

\section{DISCUSSÃO}

Os resultados deste estudo demonstraram uma prevalência de sintomas depressivos de 65,5\% em indivíduos infectados pelo HIV. Apesar desta percentagem traduzir a presença de sintomas e não propriamente o diagnóstico de depressão, o seu valor não deixa de ser alarmante, situando-se bastante acima dos $20 \%$ de prevalência de depressão que se verifica na população portuguesa [23]. Relativamente a esses achados, estima-se que a prevalência real de depressão major em indivíduos HIV positivos seja em torno os $30 \%$, embora esteja documentado que quando, à semelhança do método utilizado neste estudo, são usadas escalas de autoavaliação para sintomas depressivos em indivíduos HIV positivos, a taxa de depressão sobe dramaticamente, aproximandose dos $50 \%$ [4,9]. É possível que a taxa de sintomas depressivos se encontre sobrestimada devido à sobreposição de sintomas de depressão e da própria doença provocada pela infecção por HIV. A elevada prevalência de sintomas graves encontrados $(32,7 \%)$ alerta-nos para a importância da monitorização de sintomatologia depressiva nos doentes seropositivos. Só assim os distúrbios depressivos poderão ser diagnosticados precocemente e tratados em tempo útil.

Relativamente a antecedentes de depressão, houve diferenças marginalmente significativas entre os sexos, com $30 \%$ das mulheres tendo apresentado episódio depressivo anterior em contraste com 13,8\%, dos homens. $\mathrm{O}$ fato de não haver significância estatística em relação a estes resultados pode ser explicado pelas características da amostra discutidas anteriormente. À semelhança do que acontece na população geral, em outros estudos foram documentadas maiores taxas de depressão em mulheres seropositivas para HIV $[5,7]$.

Neste estudo não foram encontradas associações entre sintomas depressivos e os parâmetros de infecção HIV avaliados - carga viral, contagem e percentagem de CD4+. Estes achados estão em conformidade com trabalhos anteriormente realizados [7,8]. Ainda assim, continua a não haver consenso sobre esta matéria, existindo estudos que relacionam a ocorrência de episódios depressivos com a diminuição da contagem de CD4+ e consequente declínio da função imune [11].
Seriam necessários mais estudos para esclarecer se, de fato, poderá ou não haver relação entre estas variáveis.

Não obstante, foram encontradas associações entre sintomas depressivos e alguns dos outros fatores abordados neste estudo. O baixo nível de escolaridade mostrou estar associado a pior perfil depressivo em doentes HIV positivos, o que era esperado. Vink et al. [7] já o haviam demonstrado em seu estudo, no qual foi também encontrada associação entre a presença de sintomas depressivos e a situação profissional (ao contrário do que ocorreu no presente estudo).

Houve uma associação marginalmente significativa entre a existência de comorbidade psiquiátrica e os níveis de sintomas depressivos $(\mathrm{p}=0,071)$, o mesmo não se tendo verificado para a presença de comorbidade orgânica. Este achado pode ser relacionado com um estudo de Atkinson et al., [11] que apontou a presença de comorbilidade psiquiátrica como um forte preditor de depressão.

Neste estudo, os distúrbios psicóticos foram os mais frequentes entre as comorbidades psiquiátricas, constituindo $70 \%$ dos casos, quando excluídas a depressão e a dependência de substâncias. Estes resultados podem ser reflexo da maior propensão de doentes com comorbidade de foro psicótico ao contágio pelo HIV. A existência de sintomas psicóticos aumenta em grande escala o risco de infecção por esse vírus devido, principalmente, à maior probabilidade de adopção de comportamentos de risco, como o uso concomitante de drogas e a prática de relações sexuais com múltiplos parceiros [5].

Este estudo revelou que a toxicodependência se relaciona com o nível de sintomas depressivos, tendose verificado uma elevada prevalência de sintomas depressivos nesses doentes. A percentagem de toxicodependentes encontrada neste estudo foi bastante elevada, assim como em outros estudos, que referiram o abuso de substâncias como um distúrbio bastante prevalente entre indivíduos HIV positivos, podendo chegar a uma taxa aproximada de 75\% [9]. Embora a maior parte dos indivíduos toxicodependentes não se encontrasse em fase ativa de consumos, $77,5 \%$ destes encontravam-se sob terapêutica de substituição com metadona que, sendo um opióide, pode cursar com perturbações do humor [24]. Estas circunstâncias podem ter tido influência sobre os sintomas encontrados nesse grupo de doentes. Na verdade, a par dos distúrbios depressivos, a dependência de substâncias de abuso é das comorbidades psiquiátricas mais frequentes nessa população de doentes, sendo ela própria um fator de risco para a depressão [4]. 
Este estudo apresenta algumas limitações, nomeadamente no que diz respeito à técnica de amostragem. Devido a questões logísticas e de confidencialidade de dados, não foi possível a realização de uma amostragem aleatória. A amostra utilizada foi então obtida por conveniência, o que aumenta o risco de não representatividade. Adicionalmente, a amostra incluiu um número relativamente reduzido de indivíduos, com uma baixa proporção de mulheres. Embora a baixa proporção de mulheres da amostra possa ser explicada pelas características da própria população (em que apenas $23,7 \%$ do indivíduos pertenciam ao gênero feminino), estes aspectos podem, de certa forma, comprometer a generalização dos resultados.

O BDI constitui uma ferramenta de diagnóstico de sintomas depressivos e, não, de depressão. A apreciação dos sintomas é feita segundo uma escala de auto-avaliação, podendo assim haver alterações nos resultados por tendências de resposta ou pela influência da aceitabilidade social. Por outro lado, como já referido anteriormente, o BDI aborda sintomas que estão presentes na depressão e na doença por HIV e que podem constituir efeitos laterais da TARV (perda de peso, fadiga, insónia). Este fato pode contribuir para a sobrestimação de sintomas depressivos.

Quanto aos parâmetros de infecção por HIV avaliados, apesar dos esforços para que os resultados das análises fossem recentes, estas não foram realizadas em tempo real, podendo os valores analíticos registados apresentar variações relativamente aos apresentados na altura do preenchimento do BDI. À semelhança dos resultados de trabalhos anteriores, não foram encontradas associações entre a gravidade de sintomas depressivos e os parâmetros analíticos da infecção HIV avaliados (carga viral, contagem e percentagem de $\mathrm{CD} 4+)$ neste estudo. No entanto, existe ainda grande controvérsia quanto a este aspecto.

Serão necessários mais estudos para esclarecer acerca das possíveis relações entre estes fatores, em que haja maior controle sobre variáveis de confundimento, como a medicação, susceptível de causar, ela própria, sintomas depressivos. Adicionalmente, será vantajoso utilizar ferramentas mais precisas para o diagnóstico da depressão, com avaliação por médicos psiquiatras, ao invés de utilizar exclusivamente uma escala de autoavaliação de sintomas depressivos.

Apesar das limitações, pode-se concluir que os doentes HIV positivos da clínica de infectologia do HJU do Porto apresentam uma elevada prevalência de sintomas depressivos. Além disso, mais de 30\% dos indivíduos apresentavam sintomatologia depressiva grave. Os achados deste estudo reforçam assim a importância de monitorizar este tipo de sintomas nos pacientes HIV positivos, particularmente nos toxicodependentes.

A vigilância de sintomas depressivos favorece o diagnóstico precoce de depressão e consequentemente, o seu tratamento adequado. Estas simples medidas têm um importante impacto na qualidade de vida dos indivíduos soropositivos, ao mesmo tempo em que previnem a adoção de comportamentos de risco e a falha na adesão à TARV, melhorando a saúde desses pacientes, impedindo o desenvolvimento de estirpes resistentes do vírus e prevenindo a propagação do HIV.

\section{AGRADECIMENTOS}

Os autores agradecem a todo o pessoal do Hospital de Joaquim Urbano do Porto, nomeadamente ao Prof. Dr. Rui Sarmento e Castro, à Prof. Dra. Ana Horta, a Felismina Costa e à equipe de Enfermagem do Hospital de Joaquim Urbano e do CTC, em particular à Enf. Leonor.

PF e PM desenharam a pesquisa; PF efetuou a coleta de dados; PF e PM efetuaram a análise de dados; PF, PM e AF efetuaram a revisão bibliográfica e a redação do manuscrito.

\section{REFERÊNCIAS}

1. Organização Mundial de Saúde. Key facts on global HIV epidemic and progress in 2010 [Internet]. 2011 [cited 2011 November 30]. Available from: http://www.who.int/hiv/pub/progress_report2011/global_facts/en/index.html

2. National Center for HIV/AIDS, Viral Hepatitis, STD, and TB Prevention, Centers for Disease Control and Prevention. Diagnoses of HIV Infection in the United States and Dependent Areas, 2011. HIV Surveillance Report; 2011. v. 2.

3. Owe-Larsson B, Säll L, Salamon E, Allgulander C. HIV infection and psychiatric illness. Afr J Psychiatry. 2009;12:115-28. http://dx.doi. org/10.4314/ajpsy.v12i2.43729

4. Hinkin C, Castellon S, Atkinson J, Goodkin K. Neuropsychiatric aspects of HIV infection among older adults. J Clin Epidemiol. 2001;54:S44-S52. http://dx.doi.org/10.1016/S0895-4356(01)00446

5. Dubé B, Benton T, Cruess G, Evans D. Neuropsychiatric manifestations of HIV infection and AIDS. J Psychiatry Neurosci. 2005;30(4): 237-46.

6. Akena D, Musisi S, Kinyanda E. A comparison of the clinical features of depression in HIV-positive and HIV-negative patients in Uganda. Afr J Psychiatry. 2010;13:43-51. http://dx.doi.org/10.4314/ajpsy.v13i1.53429 
7. Vink F, Suliman S, Buck N, Kidd M, Seedat S. Psychopathology, fundamental assumptions and CD-4 T lymphocyte counts in HIV-positive patients. Afr J Psychiatry. 2010;13:267-74. http://dx.doi.org/10.4314/ajpsy.v13i4.61875

8. Alciati A, Ferri A, Rozzi S, Monforte A, Colmegna F, Valli I, Mellado C. Changes in Lymphocyte Subsets in Depressed HIV-Infected Patients Without Antiretroviral Therapy. Psychosomatics. 2001;42:247-51. http://dx.doi.org/10.1176/appi.psy.42.3.247

9. Treisman G, Angelino A. Interrelation between Psychiatric Disorders and the Prevention and Treatment of HIV Infection. Clin Infect Dis. 2007;45:S313-S7. http://dx.doi.org/10.1086/522556

10. Baillargeon J, Ducate S, Pulvino J, Bradshaw P, Murray O, Olvera R. The Association of Psychiatric Disorders and HIV Infection in the Correctional Setting. Ann Epidemiol. 2003;13:606-12. http://dx.doi.org/10.1016/S1047-2797(03)00061

11. Atkinson J, Heaton R, Patterson T, Wolfson T, Deutsch R, Brown S, Summers J, Sciolla A, Guiterrez R, Ellis R, Abramson I, Hesselink J, McCutchan J, Grant I. Two-year prospective study of major depressive disorder in HIV-infected men. J Affect Disorders. 2007;108: 225-34. http://dx.doi.org/10.1016/j.jad.2007.10.017

12. Baillargeon J, Paar D, Wu H, Giordano T, Murray O, Raimer B, Avery E, Diamond P, Pulvino J. Psychiatric disorders, HIV infection and HIV/hepatitis coinfection in the correctional setting. AIDS Care. 2008;20(1):124-9. http://dx.doi.org/10.1080/09540120701426532

13. Gupta R, Dandu M, Packel L, Rutherford G, Leiter K, Phaladze N, Korte F, Iacopino V, Weiser S. Depression and HIV in Botswana: A Population-Based Study on Gender-Specific Socioeconomic and Behavioral Correlates. PLoS One. 2010;5(12):e14252. http://dx.doi. org/10.1371/journal.pone.0014252

14. Leserman J, Pence B, Whetten K, Mugavero M, Thielman N, Swartz M, Stangle D. Relation of Lifetime Trauma and Depressive Symptoms to Mortality in HIV. Am J Psychiatry. 2007;164:1707-13. http://dx.doi.org/10.1176/appi.ajp.2007.0611175

15. Schlebusch L, Vawda N. HIV-infection as a self-reported risk fator for attempted suicide in South Africa. Afr J Psychiatry. 2010;13:280-3. http://dx.doi.org/10.4314/ajpsy.v13i4.61877

16. Nduna M, Jewkes R, Dunkle K, Shai N, Colman I. Associations between depressive symptoms, sexual behaviour and relationship characteristics: a prospective cohort study of young women and men in the Eastern Cape, South Africa. J Int Aids Soc. 2010;13:44 http://dx.doi.org/10.1186/1758-2652-13-44

17. Olisah O, Baiyewu O, Sheikh T. Adherence to highly ative antiretroviral therapy in depressed patients with HIV/AIDS attending a Nigerian university teaching hospital clinic. Afr J Psychiatry. 2010;13:275-9. http://dx.doi.org/10.4314/ajpsy.v13i4.61876

18. Glover D, Garcia-Acarena E, Lester P, Rice E, Rothram-Borus M. Stress Biomarkers as Outcomes for HIV+ Prevention: Participation, Feasibility and Findings Among HIV+ Latina and African American Mothers. AIDS Behav. 2009;14:339-50. http://dx.doi.org/10.1007/ s10461-009-9549

19. Vaz-Serra, A., \& Abreu, J. Aferição dos quadros clínicos depressivos I: Ensaio de aplicação do "Inventário Depressivo de Beck" a uma amostra portuguesa de doentes deprimidos. Coimbra Médica. 1973;20:623-44.

20. Maia A. Modelos de avaliação da experiência depressiva.Psiquiatria Clínica. 2001;22(2):197-204

21. Ribeiro J. Avaliação em Psicologia da Saúde: instrumentos publicados em português. Quarteto editor: Coimbra; 2007.

22. Centers for Disease Control and Prevention. Appendix B: Comparison of the revised world health organization and surveillance case definitions and staging sydtems for HIV infection [Internet]. 2008 [updated 2008 November 20; cited 2011 December 20]. Available from: http://www.cdc.gov/mmwr/preview/mmwrhtml/rr5710a3.htm

23. Ministério da Saúde. Depressão [Internet]. 2006 [updated 2006 January 02; cited 2011 December 19]. Available from: http://www. portaldasaude.pt/portal/conteudos/enciclopedia $+\mathrm{da}+$ saude/ministeriosaude/saude + mental $/$ depressao.htm?wbc_purpose=basic

24. Caramona M, Esteves A, Gonçalves J, Macedo T, Mendonça J, Osswald W, Pinheiro R, Rodrigues A, Sampaio C, Sepodes B, Teixeira A. Sistema Nervoso Central, In: Prontuário Terapêutico - 9, INFARMED/Ministério da Saúde. Lisboa: Ministério da Saúde; 2010. p. 142-3. C 